\title{
Habermas y la política del reconocimiento o multiculturalismo
}

\author{
Luiz Bernardo Leite Araujo ${ }^{1}$
}

Trabajo recepcionado: junio 2007

Trabajo aceptado: julio 2007

\begin{abstract}
RESUMEN
El presente artículo desarrolla algunos aspectos centrales de la política del reconocimiento o multiculturalismo en la obra de Habermas. Su posición acerca del multiculturalismo está determinada por la comprensión democrático-procedimental de los derechos que se presentan en sus líneas generales y esboza algunos aspectos críticos jurídicos, políticos y filosóficos de la política de la diferencia. Se trata de una posición peculiar que permite a Habermas valorizar el aporte de la posición de Ch. Taylor, y al mismo tiempo cuestionar determinadas políticas de la diferencia, que contribuyen decisivamente a la inclusión de los ciudadanos a los cuales es negado el pleno reconocimiento como miembro de una comunidad política. Tal posición llama la atención acerca de las potenciales amenazas a la autonomía individual asociadas a las demandas específicas de grupos, particularmente en lo atingente a los derechos culturales. En el marco de los recientes debates multiculturales, se destaca que la postura de Habermas se caracteriza por un difícil equilibrio entre igualdad y diversidad, defendiendo una concepción universalista sensible a las diferencias
\end{abstract}

PALABRAS CLAVE: Habermas-Taylor, política del reconocimiento, multiculturalismo, filosofía política contemporánea.

\begin{abstract}
This research develops some central aspects about the politics of recognition or multiculturalism in the work of Habermas, showing that his position on the issue is determined by a procedural-democratic understanding of rights, presenting generally which are they and advancing some critical juridical, political and philosophical aspects of the politics of difference. The position taken by the German author allows him to value Charles Taylor's position, and also, to question some of the politics of difference that contributes decisively to citizens that had been denied the complete recognition as members of the political community. In fact, that position call for attention about the specific demand, particularly regarding to cultural rights. In the context of recent multicultural debates, it is highlighted Habermas' positions since they are characterized by a difficult equilibrium between equality and diversity, defending a universalistic conception that is sensible to differences.
\end{abstract}

KEY WORDS: Habermas-Taylor, politics of recognition, multiculturalism, contemporary political philosophy.

1 Doctor en Filosofía por la Universidad Católica de Lovaina (Bélgica), Profesor del Departamento de Filosofía de la Universidad del Estado de Río de Janeiro (UERJ) e Investigador del Consejo Nacional de Desarrollo Científico y Tecnológico (CNPq) de Brasil. 
Revista CUHSO volumen $14 \mathrm{n} \div 1$

El tema del multiculturalismo ocupa la atención de Habermas desde el momento en que irrumpe en la escena principal del debate filosófico político contemporáneo. Si la década de los ochenta del siglo pasado fue dominada ampliamente por el debate entre liberalismo y comunitarismo, cuyo foco central residía en la doble oposición entre lo justo y lo bueno, por un lado, y entre el individuo y la comunidad, por el otro ${ }^{2}$, la década de los noventa trajo a la actualidad una pregunta sobre si, y en qué medida, las sociedades democráticas deberían ser realmente caracterizadas en función del conjunto de los derechos básicos individuales que ellas aseguran a sus ciudadanos. En efecto, para diversos autores, asociados de modo más o menos estricto a lo que convencionalmente se denomina multiculturalismo, las decisiones políticas en sociedades democráticas pluralistas deberían asegurar también derechos específicos a los grupos. Nociones tales como "derechos colectivos", "derechos de grupos" y "derechos culturales" pasaron a dominar los debates políticos, una vez establecido como el núcleo de una sociedad justa la idea de los derechos iguales para todos los ciudadanos.

Es verdad que no hay un tratamiento sistemático del tema en la teoría discursiva de Habermas, pero ciertamente hay una contribución significativa a partir de esa perspectiva teórica, comenzando por el análisis del propio término multiculturalismo y por las cuestiones implícitas en el debate. En este sentido, es notable la rápida intervención habermasiana que reconoce la contribución inicial del discurso promovido por Charles Taylor $^{3}$ en su ensayo sobre la política del reconocimiento. En su crítica, el filósofo alemán ${ }^{4}$ recoge que si bien ahora estamos delante de fenómenos relacionados con las luchas del reconocimiento de identidades colectivas $y$, por tanto, con la defensa común contra la opresión, la marginalización y el irrespeto de grupos minoritarios, primeramente definidos en términos culturales, sea en el ámbito de una cultura mayoritaria, sea al interior de la comunidad de los pueblos, hay diferentes niveles de análisis. Es necesario, por tanto, no distinguirlos solamente según la especificidad de cada lucha por el reconocimiento, sino también diferenciar los planos discursivos en los que los debates se han situado aun cuando el blanco principal sea el mismo sistema de derechos fundado en el individuo. Dentro de esos fenómenos se destacan el feminismo, la lucha de las minorías étnicas y culturales, el nacionalismo y el neocolonialismo.

Mientras la causa feminista puede ser descrita apropiadamente como de reconocimiento de una interpretación específica basada en diferencias de género, transformando así la relación entre los sexos y afectando directamente a los papeles masculinos históricamente sedimentados ${ }^{5}$, la lucha de las minorías étnicas y culturales nos habla respeto al reconocimiento de las tradiciones y de las formas de vida marginadas por una cultura mayoritaria cuyos miembros, pese al hecho de tener la autocomprensión modificada en alguna medida, no alteran necesariamente sus papeles en razón de una interpretación revisada de las conquistas e intereses de los miembros de los grupos minoritarios ${ }^{6}$. Movimientos nacionalistas, a su vez, apuntan sobre todo a la autodeterminación política de los pueblos que se ven como grupos homogéneos sobre el telón de fondo de un destino histórico común $^{7}$, y de este

2 Sobre esas dos oposiciones fundamentales, las que, a pesar de no dar cuenta enteramente del debate, suministran, sin embargo, una perspectiva general susceptible de encuadrar análisis detallados de los diversos registros de esa compleja discusión, cf. BERTEN, A., DA SILVEIRA, P., POURTOIS, H. (eds.). Libéraux et communautariens. Paris: PUF, Collection "Philosophie Morale", 1997. Leer también la excelente presentación de MULHALL, S. and SWIFT, A. Liberals and Communitarians. Oxford: Blackwell, 1992.

3 TAYLOR, C. "The politics of recognition", in: GUTMANN, A. (ed.). Multiculturalism: examining the politics of recognition. Princeton: Princeton University Press, 1994, pp. 25-73. Se trata de una edición expandida, incluyendo el comentario de Habermas (ver la nota siguiente) a la edición alemana de la obra original Multiculturalism and the "Politics of Recognition": An Essay. Princeton: Princeton University Press, 1992. Cabe destacar también, en el contexto inaugural del debate sobre el tema, la obra de Iris Young (J ustice and the Politics of Difference. Princeton: Princeton University Press, 1990) que declaradamente buscaba una alternativa entre el individualismo atomista y el comunitarismo colectivista a través del foco preferencial en la diversidad de los grupos étnicos y culturales.

4 HABERMAS, J. "Struggles for Recognition in the Democratic Constitutional State", in: GUTMANN, A. (ed.). Multiculturalism: examining the politics of recognition, op. cit., pp. 107-148 (republicado en: HABERMAS, J. The inclusion of the other: studies in political theory. Cambridge (Mass.): The MIT Press, edited by Ciaran Cronin and Pablo De Greiff, 1998, pp. 203-236).

5 Para una visión general de la política feminista, cf. BENHABIB, S. "Multiculturalism and Gendered Citizenship", in: The Claims of Culture: equality and diversity in the global era. Princeton: Princeton University Press, 2002.

6 Sobre el enfoque en minorías nacionales y grupos étnicos, cf. KYMLICKA, W. Multicultural Citizenship: a liberal theory of minority rights. Oxford: Clarendon Press, 1995.

7 Cuánto a la cuestión del nacionalismo, cf. TAMIR, Y. Liberal Nationalism. Princeton: Princeton University Press, 1993; MILLER, D. On Nationality. Oxford: Oxford University Press, 1995; GANS, C. The Limits of Nationalism. Cambridge: Cambridge University Press, 2003. 
modo pretenden construir una comunidad de destino, al paso que el anti-colonialismo se dirige contra un orden internacional basado en una hegemonía de la cultura occidental ${ }^{8}$, cuyos valores se imponen de forma intervencionista en nombre de la universalidad. Pero por más vinculados que estén unos con otros, tales fenómenos no pueden ser confundidos, so pena de oscurecer la complejidad de una realidad marcada por la diversidad al interior de la misma diversidad. El caso de Quebec, por ejemplo, siempre citado en la literatura multicultural, es ilustrativo de esta complejidad y debe ser situado, a juicio de Habermas, en una frontera entre el segundo y el tercer caso, en la medida en que la aspiración de la minoría francófona canadiense, aparte de referir a tendencias separatistas de un segmento de la población, tiende a tornarse en un estado dentro de un estado, lo que constituyese así otra punta del enlace federativo, de una mayoría cultural de cara a otras minorías domésticas.

En cuanto a los diferentes niveles de análisis de los fenómenos diversos, Habermas distingue el discurso político, filosófico y jurídico demostrando particular interés por el aspecto legal del problema. En el primer nivel, la controversia acerca del multiculturalismo en efecto parece renovar el debate sobre la modernidad que había sido interpretado por el autor bajo el signo de un proyecto inacabado", oponiendo ahora el radicalismo posmoderno al tradicionalismo premoderno en una nueva configuración de lo "políticamente correcto", que poco contribuye a la comprensión de la cuestión y menos aún a su solución política. En un plano filosófico, lo que está en juego es la comprensión intercultural, cuyas dificultades aparecen claramente en todos aquellos fenómenos asociados al multiculturalismo, que reintroducen el tema clásico de la racionalidad y sus pretensiones de universalidad ${ }^{10}$, tanto cognitivas como normativas, en la relación entre la sociedad global unificada y las sociedades locales fragmentadas, moviéndose entre el holismo y el contextualismo. Desde el punto de vista jurídico, la discusión fundamental que trae el multiculturalismo reside en una interpretación del Estado democrático de derecho, reveladora de una tensión entre el principio del igual tratamiento de las personas y la búsqueda de protección de sus identidades culturales, en Io que Habermas reitera sus reservas de cara al liberalismo clásico, no oponiéndole una lectura comunitarista, como la de Taylor, que adopta la falsa pista de oposición entre una política de universalización de los derechos individuales y una política de consideración de las diferencias culturales ${ }^{11}$, pero sí corrigiendo una comprensión inapropiada de los principios liberales a fin de demostrar que el sistema de derechos correctamente entendido "no es ciego a las diferencias culturales" y no precisa ser contrastado con "un modelo que introduce una noción de derechos colectivos extraña al sistema" 12

En ambos pasajes, Habermas se refiere a los dos tipos de liberalismo -procedimental y sustancial- distinguidos por Taylor, o, en la nomenclatura de Michael Walzer, liberalismo 1 y liberalismo 2, advirtiendo que no se trata de una simple corrección de la política de la igual dignidad por la política de la diferencia, pero de un ataque al núcleo individualista de la concepción moderna de libertad. En efecto, Taylor distingue en su análisis los ideales de dignidad y de autenticidad en torno a los cuales se forjó la identidad moderna, cada uno de los cuales remitiendo a un principio básico de carácter universalista, pero radicalmente diferentes uno de otro. De un lado, el principio de la igual ciudadanía fundada en derechos compartidos por todos los individuos. De otro, el principio del reconocimiento de las personas y de los grupos en su profunda alteridad. Ciertamente, el filósofo canadiense es consciente del hecho de que, en el primer caso, se trata de una potencialidad humana generalizable, basada en la misma capacidad de actuar de acuerdo con principios morales aceptables por todos los agentes racionales,

8 En relación a la justicia global y temas correlatos, cf. HELD, D. Democracy and the Global Order: from the modern state to cosmopolitan governance. London: Polity Press, 1995; RAWLS, J. The Law of Peoples; with "The idea of public reason revisited". Cambridge (Mass.): Harvard University Press, 1999; CRONIN, C. and DE GREIFF, P. (eds.). Global J ustice and Transnational Politics: essays on the moral and political challenges of globalization. Cambridge (Mass.): The MIT Press, 2002.

9 Cf. HABERMAS, J. Der philosophische Diskurs der Moderne. Frankfurt: Suhrkamp, 1985 [El discurso filosófico de la modernidad. Madrid: Taurus, trad. de Manuel J iménez Redondo, 1989].

10 Sobre el asunto, cf. HABERMAS, J. Nachmetaphysisches Denken. Frankfurt: Suhrkamp, 1988 [Pensamiento postmetafísico. Madrid: Taurus, trad. de Manuel Jiménez Redondo, 1990].

11 El término "comunitarismo" es utilizado aquí en sentido restricto, respetando una fuerte impregnación ética de la política y del derecho y no a una actitud de rechazo de la modernidad en su totalidad, que no se aplica ciertamente al análisis tayloriano. Cf. TAYLOR, C. Sources of the Self: the making of the modern identity. Cambridge (Mass.): Harvard University Press, 1989.

12 HABERMAS, J. "Struggles for Recognition in the Democratic Constitutional State", in: The inclusion of the other: studies in political theory, op. cit., pp. 207 y 210. 
mientras que, en el segundo caso, a pesar de tratarse igualmente de un potencial humano universal -es decir, de formar y definir la propia identidad como individuo y también como miembro de una cultura-, el principio del igual respeto por las personas se dirige a una particularidad. Sin embargo, es exactamente por la referencia a una característica universal, aunque distinguida, que hay exigencia de reconocimiento por aquello que resulta del potencial humano, de modo que la negación del igual respeto a las culturas infringe el principio fundamental de la igualdad. Como dice Taylor, al denunciar el primer modelo de liberalismo inhóspito a las diferencias por su aplicación uniforme de las reglas y su sospecha en relación a metas colectivas, la fuerte demanda por un igual respeto a todas las culturas se funda en la premisa de que "reconocimiento forja identidad", de forma que "todos deberían disfrutar de la suposición de que su cultura tradicional tiene valor" ${ }^{13}$. Taylor habla en suposición o aun en hipótesis inicial de igual valor de las culturas, consciente del problema de nivelar al revés, o sea, de que la política del reconocimiento puede acabar haciendo todo idéntico, pero manteniendo la tesis central, criticada por Habermas, de la divergencia entre las políticas del universalismo y de la diferencia en el seno del liberalismo.

En este punto se torna importante recordar algunos elementos establecidos por Habermas en su comprensión democráticoprocedimental de los derechos ${ }^{14}$, la cual determina su posición en el debate sobre el multiculturalismo. En efecto, su afirmación de que el sistema de derechos no es ciego a las diferencias culturales, y tampoco a las condiciones sociales desiguales, depende integralmente de una tesis fundamental adoptada por la teoría discursiva, a saber, la tesis de la relación interna, por tanto, de ningún modo contingente, entre el Estado de derecho y la democracia, para cuya demostración es necesario, en palabras de Habermas, "el esclarecimiento de las siguientes proposiciones: el derecho positivo no puede ser subsumido o sometido simplemente a la moral; la soberanía popular y los derechos humanos se presuponen mutuamente; el principio de la democracia posee raíces propias, independientes de la moral"15. Cabe destacar el hecho de que el esclarecimiento de esas proposiciones es lo que permite apuntar al equívoco de la oposición construida por Taylor entre la política universalista de la igual dignidad de todos los ciudadanos y la política del reconocimiento de las identidades de individuos y grupos, la que se basa en una interpretación paternalista del sistema de los derechos que ignora la conexión interna entre la autonomía privada y la autonomía pública. Se trata, pues, de anteponer a una lectura selectiva del liberalismo moderno una interpretación que rescate la interrelación de dos intuiciones normativas fundamentales que satisfacen el criterio moral del universalismo igualitario, que exige el respeto igual para todos, y el criterio ético del individualismo, según el cual cada persona tiene el derecho de conducir su vida de acuerdo con sus propias preferencias y convicciones.

Tal relación interna es aprehendida en base a una relectura de dos interpretaciones contrarias y conflictivas en la filosofía política, representadas por el liberalismo clásico y por el republicanismo cívico. Una tradición liberal que remonta a Locke, pone el énfasis en el carácter impersonal de las leyes y en la protección de las libertades individuales, de tal modo que el proceso democrático es compelido por (y está al servicio de los) derechos personales que garantizan a cada individuo la libertad de buscar su propia realización. Se cristaliza aquí una visión individualista e instrumentalista del papel de los ciudadanos. La ciudadanía es concebida en base a un modelo de pertenencia organizacional capaz de fundamentar una posición jurídica, o sea, los individuos permanecen exteriores al Estado, contribuyendo de cierta manera a su reproducción, a través de elecciones y pago de impuestos, a fin de conseguir a cambio, beneficios organizacionales. Por el contrario, en una tradición republicana que remonta a Rousseau, la primacía es atribuida al proceso democrático en cuanto tal, entendido como una deliberación colectiva que impele a los ciudadanos a la búsqueda de un entendimiento sobre el bien común. En esta visión, la libertad individual tiene su máxima expresión no en una

13 TAYLOR, C. "The politics of recognition", in: GUTMANN, A. (ed.). Multiculturalism: examining the politics of recognition, op. cit., pp. 66 y p. 68.

14 Me refiero al más importante tratado habermasiano en filosofía política y del derecho (al cual está directamente vinculada la obra de teoría política ya citada, publicada cuatro años después): HABERMAS, J. Faktizität und Geltung. Beiträge zur Diskurstheorie des Rechts und des demokratischen Rechtsstaats. Frankfurt: Suhrkamp, 1992. Utilizo aquí la siguiente traducción portuguesa: Direito e Democracia: entre facticidade e validade. Rio de J aneiro: Tempo Brasileiro, 2 vols., trad. de Flávio Siebeneichler, 1997.

15 HABERMAS, J. Direito e Democracia: entre facticidade e validade, op. cit., vol. 2, p. 310. 
búsqueda de preferencias privadas, sino en una autolegislación mediante la participación política. La ciudadanía es vista a través del modelo de pertenencia a una comunidad éticocultural que se determina a sí misma, o sea donde los individuos están integrados a una comunidad política como partes de un todo, de tal manera que para formar su identidad personal o social, necesitan del horizonte de tradiciones comunes y de instituciones políticas reconocidas ${ }^{16}$.

Según Habermas, las divergencias no son enteramente sorprendentes si tenemos en cuenta el hecho de que el pensamiento democrático moderno se forjó en medio de un conflicto interno entre dos nociones radicalmente distintas de libertad, paradigmáticamente comparadas por Benjamín Constant ${ }^{17}$, bajo los títulos de la libertad de los "modernos" y la libertad de los "antiguos". La tradición liberal atribuye mayor peso a la primera, sobre todo a la libertad de conciencia y de pensamiento, mientras que la tradición republicana da mayor importancia a la segunda, particularmente a las llamadas libertades políticas iguales. Siendo así, ambas concurren a partir de conceptos unilaterales que conciben, por un lado, los "derechos humanos" como expresión de autodeterminación moral, y por otro, la "soberanía popular" como expresión de autorrealización ética. De acuerdo con la interpretación liberal, los ciudadanos no se distinguen esencialmente de las personas privadas que hacen valer sus intereses prepolíticos contra el aparato estatal. Es por eso que la prioridad recae sobre las libertades negativas que aseguran el ejercicio de la autonomía individual. Según la interpretación republicana, la ciudadanía se actualiza solamente en una práctica de autodeterminación colectiva, razón por la que la primacía incide sobre la autonomía política de los ciudadanos, que constituye un fin en sí mismo y que nadie puede realizar persiguiendo privadamente sus intereses propios, pues presupone el camino común de una práctica intersubjetiva. De este modo, el liberalismo y el republicanismo tienden a resaltar apenas unos de los aspectos de la autonomía de los individuos como base de la legitimidad democrática. Al defender una relación interna entre autonomía privada y autonomía política, la Teoría del Discurso pretende hacer justicia a ambas tradiciones, esto es, proporcionar una justificación del estado de derecho democrático en el que los derechos humanos y la soberanía popular desempeñan papeles diferentes, irreductibles, aunque complementarios.

Es de una tal justificación que proviene el modelo procedimental de la teoría discursiva de la moral y de la política, una vez que para demostrar la tesis de una relación interna entre democracia y estado constitucional, es necesario introducir un principio de validación imparcial de normas, conceptualmente anterior a la propia distinción entre la moral y el derecho, cuya formulación es la siguiente: "sólo pueden pretender validez las normas de acción que puedan contar con el asentimiento de todos los afectados como participantes en discursos racionales"18. El principio del discurso (D) permite evitar tanto una interpretación moralizante del derecho como su confinamiento en afirmaciones comunitarias de valores compartidos, apuntando a un modelo de legitimación que suelda la escisión liberal-republicana. De cara al problema de la integración de las sociedades modernas pluralizadas y secularizadas, en las cuales los órdenes normativos deben ser mantenidos sin las garantías metasociales de naturaleza religiosa o metafísica, Habermas adopta una comprensión procedimental de la razón práctica en cuyo centro está la expectativa de la cualidad racional de los resultados obtenidos a través de una amplia y libre discusión entre los participantes de los procesos argumentativos fundados en el principio del discurso. En la calidad de principio de justificación imparcial de las normas de acción en general, el principio del discurso (D) está igualmente en la base de la moralidad y del derecho. Y es gracias a una diferenciación de los usos de la razón práctica ${ }^{19}$ que Habermas insiste en el delineamiento sutil entre tal principio, que explicita el sentido de la imparcialidad de los juicios prácticos, y su especificación como principio moral (U), según el que "cada norma

16 Sobre esos dos conceptos concurrentes de ciudadanía, cf. HABERMAS, J. "On the relation between the nation, the rule of law and democracy", in: The inclusion of the other: studies in political theory, op. cit., pp. 129-153.

17 Cf. CONSTANT, B. "De la liberté des anciens comparée a la celle des modernes", in: De l'esprit de conquête et de I'usurpation. París: Flammarion, 1986, pp. 265-291 [La edición original es de 1819].

18 HABERMAS, J. Direito e Democracia: entre facticidade e validade, op. cit., vol. 1, p. 142.

19 Habermas distingue las dimensiones ética, pragmática y moral de la razón práctica. Las cuestiones éticas dicen respeto a aquello que es bueno para mí o para nosotros, mientras que las cuestiones pragmáticas se refieren a medios apropiados para determinados fines prácticos. Las cuestiones morales, a su vez, tienen que ver con lo que es válido para todos, en el sentido kantiano de un deber universal. Leer, en particular: HABERMAS, J. Erläuterungen zur Diskursethik, op. cit., pp. 100-118. 
válida habrá de satisfacer la condición de que las consecuencias y efectos secundarios que se siguen de su acatamiento general para la satisfacción de los intereses de cada persona (presumiblemente) puedan resultar aceptados por todos los afectados" 20 - o como el principio de la democracia (De)- de acuerdo con el cual "sólo pueden pretender validez legítima las leyes jurídicas capaces de encontrar el asentimiento de todos los ciudadanos en un proceso discursivo de legislación que, a su vez, ha sido legalmente constituido" ${ }^{21}$. La nueva formulación del principio del discurso (D) posee una doble ventaja, producto de su alto grado de abstracción, en relación a aquella presentada originalmente por Habermas ${ }^{22}$. En primer lugar, las normas de acción a las que se refiere no prejuzgan el contexto en que están insertas, cabiendo al principio de la democracia (De) la especificación como normas que manifiestan las propiedades formales de las normas jurídicas. En segundo lugar, los discursos racionales envuelven varias formas de argumentación que están abiertas a las contribuciones e informaciones relacionadas a temas morales, ético-políticos y pragmáticos, e incumbe al principio moral (U) la restricción del amplio espectro de cuestionamientos para el tipo de discurso en el cual solo argumentos morales son decisivos.

Aunque distintos, los principios de la moral y la democracia no están ordenados jerárquicamente. Para Habermas, al contrario, ellos son complementarios, de tal modo que la legitimidad jurídica no puede ser asimilada a la validez moral, como en el caso del iusnaturalismo, y tampoco el derecho debe ser completamente separado de la moral, como defiende el positivismo. El derecho es comprendido como un complemento funcional de la moralidad postradicional, compensando así mucho de su déficit, como la indeterminación cognitiva y la incerteza motivacional. Además de esto, Habermas defiende que el principio de la democracia no está subordinado a un sistema de derechos, sino que ellos se constituyen de modo cooriginario, explicándose recíprocamente. "Por eso -afirma el autor- el principio de la democracia solo puede aparecer como núcleo de un sistema de derechos" ${ }^{23}$. La idea básica es que el sistema de derechos debe ser desarrollado o desenvuelto a partir de la interligazón entre el principio del discurso y la forma jurídica, proceso al que Habermas da el nombre de "génesis lógica de los derechos". Tal sistema de derechos, reconocido por ciudadanos que desean regular la vida en común por medio del derecho positivo, delinea las condiciones generales necesarias para la institucionalización de procesos democráticos de discusión en el ámbito del derecho y de la política. Habermas apunta cinco categorías básicas de derechos, los que incluyen: a los derechos a la mayor medida posible de iguales libertades subjetivas de acción, al estatuto de miembro en la comunidad política, a la protección jurídica individual, al ejercicio de la autonomía política y a las condiciones básicas de vida que pueden garantizar la oportunidad de ejercer las otras categorías de derechos explicitados. "Cuando introducimos el sistema de derechos de esta manera", concluye Habermas, "se torna comprensible la interligazón entre soberanía popular y derechos humanos, por tanto la co-originariedad de la autonomía política y de la privada. Con eso no se reduce el espacio de la autonomía política de los ciudadanos a través de los derechos naturales o morales, que apenas esperan ser colocados en vigor, ni se instrumentaliza simplemente la autonomía privada de los individuos para los fines de una legislación soberana. Nada viene antes de la práctica de autodeterminación de los ciudadanos, a no ser, de un lado, el principio del discurso, que está inserto en las condiciones de socialización comunicativa en general, y de otro lado, el médium del derecho" ${ }^{24}$. Como se puede notar, la cuestión central de la legitimidad es abordada a través de la racionalidad propia del derecho moderno, asegurada por el vínculo entre la autonomía privada y la autonomía

20 HABERMAS, J. Conciencia moral y acción comunicativa. Barcelona: Península, trad. de Ramón García Cotareto, 1985, pp. 85-86 [Moralbewusstsein und kommunikatives Handeln. Frankfurt: Suhrkamp, 1983].

21 HABERMAS, J. Direito e Democracia: entre facticidade e validade, op. cit., vol. 1, p. 145.

22 Cerca de diez años antes, Habermas había formulado de la siguiente manera el principio D: “únicamente pueden aspirar a la validez aquellas normas que consiguen (o puedan conseguir) la aprobación de todos los concernidos en cuanto participantes de un discurso práctico" (Conciencia moral y acción comunicativa, op. cit., p. 117; traducción modificada, donde se dice de modo tautológico "los participantes en cuanto participantes"). Al hablar ahora en "normas de acción" en general, sin expresar un sentido específico de validez normativa, y en "discursos racionales", que pueden comportar justificaciones discursivas de carácter moral, ético y pragmático, Habermas considera que existe un espacio amplio para la deducción de los principios de la moral (U) y la democracia (De), desde el principio del discurso (D), por medio de especificaciones adecuadas.

23 HABERMAS, J. Direito e Democracia: entre facticidade e validade, op. cit., vol. 1, p. 158

24 Idem, Ibidem, pp. 164-165. 
pública de ciudadanos integrados socialmente a través de la acción comunicativa ${ }^{25}$.

El modelo habermasiano de la democracia procedimental -término que sirve para designar la tentativa de realización de los derechos vinculados a las dos formas de autonomía de los ciudadanos por la incorporación de los discursos pragmáticos, ético-políticos y morales en marcos institucionales- es introducido también por el contraste entre las alternativas clásicas: republicana y liberal. Como el modelo republicano, rechaza una visión del proceso político como siendo, primariamente, el de competencia entre preferencias privadas. Como el modelo liberal, entretanto, considera la visión de una ciudadanía unificada y activamente motivada por una visión compartida del mundo irrealista en las sociedades modernas pluralistas. En verdad, tales modelos proceden de un mismo concepto de sociedad centrado en el Estado aunque este último sea tenido, en un caso, como protector de una sociedad económica, y en otro caso, como la institucionalización de una comunidad ética. En una visión liberal, la constitución del Estado de derecho es el aspecto capital del equilibrio de los intereses de los sujetos privados que buscan la satisfacción de sus expectativas concurrentes. En una visión republicana, la formación de una comunidad ético-política estructurada es el elemento central para la autodeterminación democrática de los sujetos vinculados a una totalidad colectiva. La primera perspectiva prescinde de la idea de ciudadanía y del papel constitutivo de la formación política de la opinión y de la voluntad, mientras que la segunda menoscaba las fronteras entre el Estado y la sociedad civil a través de una excesiva politización de una esfera pública vuelta contra la administración burocrática ${ }^{26}$.

Ambos elementos de normativización constitucional y del proceso político de formación de la opinión y de la voluntad son asumidos bajo nueva composición en la teoría discursiva de la democracia: "para ella los procesos y presupuestos comunicativos de formación democrática de la opinión y de la voluntad funcionan como la compuerta más importante para la racionalización discursiva de las decisiones de un gobierno y de una administración vinculadas al derecho y a la ley"27. Habermas sugiere un proceso en dos vías, uno en el que hay una división del trabajo entre el "público débil", la esfera pública informalmente organizada, que comprende asociaciones privadas, instituciones culturales, grupos de interés con preocupaciones públicas, iglesias, instituciones de caridad, etc. y el "público fuerte", las corporaciones parlamentarias y otras instituciones formalmente organizadas del sistema político. La soberanía popular interpretada de modo intersubjetivista no se concentra en un actor colectivo que refleja la totalidad y actúa en función de ella, como en el modelo republicano, y tampoco es proscrita para el anonimato de competencias jurídicas-constitucionales, como en el modelo liberal, pero se hace valer como poder producido comunicativamente. En este sentido, los discursos institucionalizados para la formación política de la opinión y de la voluntad son vitales para el ejercicio de la ciudadanía, en la medida en que el proceso democrático impele a los participantes al compromiso en perspectivas recíprocas y a la búsqueda de intereses generalizables. El eje de una comprensión genuinamente procedimental de la democracia en los términos de Habermas, "consiste precisamente en el hecho de que el proceso democrático institucionaliza discursos y negociaciones con el auxilio de formas de comunicación que deben fundamentar la suposición de racionalidad para todos los resultados obtenidos conforme el proceso", siendo su núcleo dogmático, en el sentido de algo que no podemos eludir, "la idea de autonomía según la cual los hombres actúan como sujetos libres en la medida que obedecen a las leyes que ellos mismos establecen, sirviéndose de nociones adquiridas en un proceso intersubjetivo" ${ }^{28}$.

La posición de Habermas en el debate en torno del multiculturalismo, como ya fue destacado, es determinada por la comprensión democrático-procedimental de los derechos que intentamos presentar en sus líneas generales. Se trata de una posición peculiar que permite al autor cuestionar determinadas políticas de la diferencia, que contribuyen decisivamente a la inclusión de los ciudadanos a los cuales es negado el pleno reconocimiento como miembro de una comunidad política, y al mismo tiempo llamar la atención acerca de las potenciales amenazas a la autonomía individual asociadas a las demandas específicas de grupos, particularmente en lo atingente

25 Para una exposición sucinta de la teoría política habermasiana: "On the internal relation between the rule of law and democracy", in: The inclusion of the other: studies in political theory, op. cit., pp. 253-264.

26 Para una breve presentación del modelo habermasiano de democracia: "Three normative models of democracy", in: The inclusion of the other: studies in political theory, op. cit., pp. 239-252.

27 HABERMAS, J. Direito e Democracia: entre facticidade e validade, op. cit., vol. 2, p. 23

28 Idem, Ibidem, pp. 27 y 190. 
a los Ilamados derechos culturales. De este modo, como en muchos otros temas tratados en el ámbito de la teoría discursiva, la postura de Habermas, en los recientes debates multiculturales, se caracteriza por un difícil equilibrio entre la igualdad y la diversidad, defendiendo una concepción universalista sensible a las diferencias. Entretanto, hay duda sobre la superioridad de su óptica - comparada con las alternativas del liberalismo y del republicanismo, tales como presentadas por el pensador alemán ${ }^{29}$ para tratar con diferencias políticamente significativas de grupos étnicos, nacionales y religiosos ${ }^{30}$. En este sentido, no son pocas las críticas al modo discursivo del tratamiento de la cuestión, ya sea porque subestima la importancia de las identidades culturales, sea por no ser suficientemente atento a la relevancia de la cultura en el campo de la política, sea también en razón de no reconocer la profundidad de la diversidad y de los conflictos de los valores en las sociedades pluralistas contemporáneas ${ }^{31}$. En breves palabras, el desafío parece residir en una comprobación de que el tipo de normatividad que subyace a una interpretación democrática radical del liberalismo político permite conjugar de modo satisfactorio el ideal igualitario de la ciudadanía democrática y las demandas legítimas de individuos y grupos a los que las normas, aunque justificadas desde el punto de vista de los intereses de todos, imponen restricciones diferenciadas.

El desafío es enfrentado por Habermas al enfocar tres aspectos interligados y directamente vinculados con el tema del multiculturalismo: la idea liberal de igualdad, los derechos de los grupos, y el igual tratamiento de las culturas. En el primer caso, el objetivo es la defensa de la igualdad cívica contra las tentativas de desconstrucción del liberalismo.

En el segundo, se trata de apuntar a las consecuencias ambivalentes de los derechos de los grupos fundados por el multiculturalismo, los que normalmente producen lo que Habermas llama una transformación dialéctica de igualdad en represión. En el tercer caso, se examina la consistencia conceptual de la intersección de libertad e igualdad en casos de igual tratamiento de las culturas, problema que tiene que ver justamente con la razonabilidad normativa de los costos que los individuos y grupos deben pagar por una adaptación a la modernización cultural y social ${ }^{32}$. Tales aspectos, brevemente tratados a continuación, acaban reforzando algunos tópicos del abordaje habermasiano acerca de la cuestión del multiculturalismo, destacándose sobre todo las siguientes tesis: (a) apenas un universalismo igualitario sensible a las diferencias puede predicar los requisitos indispensablespara la protección de la integridad vulnerable de los individuos con historias de vida distintas; (b) aunque la implementación de los llamados derechos culturales para los miembros de grupos discriminados de modo semejante a los derechos sociales, siga un desarrollo jurídico gobernado por el principio de igualdad cívica, es fundamental que tal expansión del concepto clásico de ciudadanía no viole los derechos individuales en nombre de los derechos colectivos, los que no siendo sospechosos per se, en el entender de Habermas, son legítimos en la medida que derivan de los derechos culturales de un miembro individual del grupo; (c) y por último, no solo las normas, sino también las restricciones asimétricas de ellas derivadas, aceptables en las bases normativas, son una expresión del principio de igualdad cívica que dirige el uso público de la razón.

29 El destaque es importante, pues la presentación habermasiana de las dos interpretaciones contrarias y conflictivas en la filosofía política posee valor heurístico y, en esa medida, destaca las características principales de forma estilizada. Es notorio, por ejemplo, el sentido "comunitarista" de ese republicanismo contrastado con el liberalismo. Se sabe, sin embargo, que ni el liberalismo ni el republicanismo constituyen tradiciones políticas homogéneas, de modo que muchos de sus representantes son encuadrados en ambas, como es el caso de Rawls y también del mismo Habermas (como intenté demostrar en el texto "A prioridade do justo sobre o bem no liberalismo político e na teoria discursiva", en: OLIVEIRA, N.; SOUZA, D. G. (eds.). J ustiça e Política. Porto Alegre: EDIPUCRS, pp. 29-45). Acerca de la lectura habermasiana del republicanismo, cf. BERTEN, A. "Républicanisme et motivation politique", en: MERLE, J. C.; SCHUMACKER, B. (eds.). Figures du communautarisme. París: Ophrys, 2001.

30 La duda es lanzada en la propia introducción, hecha por Cronin y De Greiff para la obra The inclusion of the other. De hecho, los editores afirman que "Ias teorías altamente abstractas de los derechos humanos y de la soberanía popular en las cuales él propone fundar la democracia tanto en el nivel nacional cuanto en el nivel supranacional parecen ignorar los valores culturales que moldean las identidades de grupos" ["Editor's Introduction”, pp. vii-xxxii; aquí, p. xxviii], sin dejar de notar la fuerza y la originalidad de Habermas al tratar de una amplia gama de cuestiones en el cuadro de una filosofía política singular.

31 Cf. YOUNG, I. "Communication and the Other: Beyond Deliberative Democracy", in: BENHABIB, S. (ed.). Democracy and difference: contesting the boundaries of the political. Princeton: Princeton University Press, 1996, pp. 120-135; BAUMEISTER, A. "Habermas: Discourse and Cultural Diversity". Political Studies, 51 (2003): 740-758. THOMASSEN, L. "The Inclusion of the Other? Habermas and the Paradox of Tolerance". Political Theory, 34 (2006): 439-462.

32 Cf. HABERMAS, J. "Equal Treatment of Cultures and the Limits of Postmodern Liberalism". The J ournal of Political Philosophy, 13 (2005): 1-28. Esos tres aspectos permiten a Habermas retomar, cerca de diez años después de los comentarios a la política del reconocimiento de Taylor, el tema del multiculturalismo en la ocasión de una crítica a la lectura posmoderna del liberalismo, recientemente promovida por Christoph Menke, cuya bibliografía puede ser encontrada a lo largo de las dos primeras secciones del artículo de Habermas. Vide, entre uno y otro texto, el siguiente: "Religious Tolerance - The Pacemaker for Cultural Rights". Philosophy, 79 (2004): 5-18. 
En relación al primer aspecto, se trata de una objeción inspirada en una crítica de la razón que pretende demostrar la naturaleza autocontradictoria del concepto de igualdad política, el cual inevitablemente fracasa ante la relación paradójica entre el igual tratamiento y la realización de la justicia en los casos individuales, como podría ser ilustrado por la concepción modular del consenso sobrepuesto de Rawls ${ }^{33}$. De acuerdo con la crítica desconstruccionista, el problema no reside tanto en la formulación de un liberalismo estrictamente político que evita apoyarse en las doctrinas morales, filosóficas y religiosas que componen una sociedad democrática, ya que la búsqueda de la justicia con base en el igual tratamiento de todos los ciudadanos representa una idea básica de cualquier programa liberal, pero sí en la necesaria marginalización de las concepciones del bien que no comparten la visión substantiva y particular de la vida correcta expresa en el propio principio de la igual libertad, de modo que el establecimiento de la justicia está destinado al malogro por razones conceptuales. Lo que está en juego, evidentemente, es el problema de la neutralidad de un orden político justo en relación a la doctrinas comprensivas, frente al cual Rawls distingue claramente dos sentidos: lo de la neutralidad de "objetivo" 0 "meta" (aim) y lo de la neutralidad de "efecto" o "influencia" 34 . En el primer sentido, que es el adoptado por el liberalismo político, Habermas apunta el carácter selectivo de la lectura de la desconstrucción, incapaz de examinar los pasos de la historia constitucional moderna de implementación de los derechos básicos bajo la óptica de un proceso de aprendizaje que puede ser reconstruido por medio de varios ejemplos -como aquellos fenómenos mencionados en el inicio de este artículo- de Iuchas del reconocimiento. El otro sentido de la neutralidad, rechazado por Rawls, trae a la superficie el problema específico -estudiado por separado por Habermas, como veremosde la exclusión de visiones fundamentalistas de mundo y de grupos iliberales, pero tampoco destruye el principio de la igualdad política a punto de significar una concesión al desconstruccionismo, en la medida en que los efectos diferenciados de las normas justificadas imparcialmente sobre la autocomprensión ética y la forma de vida de cada ciudadano, como individuo y como miembro de un grupo, deben ser tratados no solo en la perspectiva de la primera persona que busca realizar su proyecto racional de vida, pero también en la perspectiva del participante involucrado en la formación de la opinión y de la voluntad política razonable. Esas perspectivas no encuentran solución satisfactoria en términos de simbiosis y deben ser mantenidas vinculadas de modo asimétrico por buenas razones normativas, tales como la consideración moral por los otros y la reciprocidad de la colegislación democrática.

Con respecto al segundo aspecto de los derechos de grupos, Habermas subraya la tensión entre la facticidad y la validez del sistema de derechos, cuya realización integral parece exigir la implementación de derechos culturales para los miembros de grupos discriminados con miras a corregir efectos asimétricos irrazonables de las normas gobernadas por el principio de la igualdad cívica. Su interés incide en los casos en que el reconocimiento mutuo de la igualdad de los ciudadanos es violado en la dimensión fundamental de la pertenencia a una misma cultura política liberal, la cual requiere una transformación delasrelacionesinterpersonales para la superación de una inclusión incompleta y desigual de los miembros de la comunidad política. Por esa razón, Habermas reconoce la importancia de la distinción analítica entre las dimensiones de la justicia social, que "concierne a la relaciones verticales entre ciudadanos de una sociedad estratificada", y de la pertenencia, que "se refiere a la relaciones horizontales entre miembros de la comunidad política", ambas inherentes a la noción de igualdad cívica, cuya realización plena es medida, por un lado, según la justa distribución de oportunidades y recursos, y, por otro, de acuerdo con el reconocimiento recíproco de derechos culturales ${ }^{35}$. Sin embargo, si es incorrecta la incorporación de

33 Cf. RAWLS, J. Political Liberalism. New York: Columbia University Press, paperback edition with a new introduction, 1996 (especialmente la cuarta lección: "The Ideal of an Overlapping Consensus", pp. 133-172).

34 Vide la quinta lección ("The Priority of Right and Ideas of the Good"), in: Ídem, Ibidem, pp. 172-211.

35 HABERMAS, J. "Equal Treatment of Cultures and the Limits of Postmodern Liberalism", op. cit., p. 16. De ahí que la aprobación de Habermas a la posición de Brian Barry, de acuerdo con la cual la cultura no es el tipo correcto de entidad suj eta a funcionar como portadora de derechos, viene acompañada de un reproche al hecho de que el punto de los derechos culturales se pierde cuando los mismos son incorporados al modelo del bienestar social, ocurriendo así una asimilación indebida de las convicciones a la preferencias. De hecho, como observa Habermas en una nota en la página indicada, el autor afirma que "la posición en relación a preferencias y a creencias es similar" (BARRY, B. Culture and Equality: an egalitarian critique of multiculturalism. Cambridge (Mass.): Harvard University Press, 2002, p. 36). Para un examen filosófico del tema, cf. FRASER, N.; HONNETH, A. Redistribution or Recognition? A Political-Philosophical Exchange. London: Verso, 2003. Sobre la obra de Barry, cf. KELLY, P. (ed.). Multiculturalism Reconsidered: 'Culture and Equality' and its Critics. Oxford: Polity Press, 2002. 
la política del reconocimiento en la política de la distribución, no es menos incorrecto, para Habermas, asimilar una comprensible introducción de derechos colectivos, que garantiza el acceso de todos los individuos a un trasfondo cultural, al falso modelo de derechos suplementarios que vendrían a corregir la política de la igualdad. Aunque la introducción de derechos de grupos haga emerger nuevos conflictos, diferentes de las disputas tradicionales entre individuos, de un lado, y entre el individuo y el Estado, de otro, el caso ej emplar de la potencial opresión interna a los grupos demuestra que la legitimidad de los derechos colectivos que aseguran el igual tratamiento de grupos culturales solo puede derivar de la demostración de que no violan necesariamente los derechos básicos de los miembros individuales de los grupos. En este sentido, el rechazo habermasiano del multiculturalismo fuerte, que no lleva en cuenta ese requerimiento y adopta "una estrategia de justificación que no excluye derechos colectivos que potencialmente restringen derechos básicos" ${ }^{36}$, reside en el hecho de que derechos no se refieren directamente a recursos culturales, y sí a sus beneficiarios, haciendo impropia la aplicación del modelo de la preservación de las especies naturales a la cultura, que no es en sí misma portadora de derechos "porque no puede encontrar las condiciones de su reproducción con su propio poder, pero depende de la apropiación constructiva por intérpretes autónomos que dicen sí o no" ${ }^{37}$.

Esa última observación en torno a una apropiación reflexiva de las tradiciones culturales hace surgir la cuestión sobre la equidad de las presiones por adaptación requeridas por el orden liberal a las doctrinas comprensivas que no comulgan de su credo político. Habiendo rechazado el argumento de una autocontradicción inherente al concepto de igualdad cívica en virtud de la realización solo parcial de la llamada neutralidad de objetivo, Habermas trata del problema de las restricciones diferenciadas impuestas a la comunidades y doctrinas tradicionales cuyos valores y creencias fundamentales no se encajan integralmente en el cuadro político del orden jurídico tallado al modo del universalismo igualitario de una moralidad posconvencional, que promueve la tolerancia mutua como conditio sine qua non para la integración de los ciudadanos en una cultura política democrática. En este sentido, el sistema moderno de tolerancia religiosa, cuya justificación está vinculada en términos conceptuales a la democracia como base de legitimación de un Estado secularizado, representa un precursor de los derechos culturales actualmente reivindicados, una vez que "la demanda cognitiva hecha por el Estado liberal a las comunidades religiosas es exactamente la misma para las comunidades seculares 'fuertes' (como minorías nacionales o étnicas, poblaciones inmigrantes o indígenas, descendientesdeesclavos, etc. ). Lastradiciones por ellos proseguidas abren 'perspectivas de mundo' que, como las imágenes religiosas de mundo, pueden entrar en conflicto unas con las otras. Así pues, hay una igual expectativa de que grupos culturales adapten su ethos interno a los padrones igualitarios de la comunidad alrededor" ${ }^{38}$. Pero, aunque la exigencia sea idéntica, los recursos conceptuales no son los mismos, especialmente cuando la cultura en cuestión está entrelazada con una visión religiosa de mundo, para la cual el requisito institucional de la separación entre la religión y la política no puede ser transformado en una carga adicional indebida que exigiría una especie de partición de la identidad en un aspecto público y en otro privado, obligando cada individuo, en la condición de miembro de una comunidad política, a expresar y a justificar sus convicciones y creencias solo en un lenguaje secularizado ${ }^{39}$. Tal asimetría impone costos desigualmente distribuidos entre los ciudadanos en consecuencia de los efectos no neutros de la tolerancia, razón por la cual,

36 Idem, Ibidem, p. 20

37 Id., Ibid., p. 22. En una mención aprobatoria de la reflexión habermasiana, Brian Barry contrasta el movimiento de "renovación cultural" de un tradicionalismo consciente de sí mismo con el conservadorismo de una posición multiculturalista fuerte (cf. BARRY, B. Culture and Equality: an egalitarian critique of multiculturalism, op. cit., p. 259), destacando justamente el argumento en favor del valor incondicional de la diversidad por analogía con el valor de la biodiversidad, como en la frase de Bhikhu Parekh: “Si estamos preparados para preservar especies botánicas y zoológicas raras, aún cuando no vemos en la actualidad su valor, no tiene sentido destruir modos de vida que no causan daños obvios e identificables a sí mismos o a otros" (apud Culture and Equality, p. 134; la ironía de Barry, al comentar ese pasaje, es demoledora: "Hay tantas cosas erradas con eso que es difícil saber por donde comenzar"). 38 HABERMAS, J. "Religious Tolerance - The Pacemaker for Cultural Rights", op. cit., p. 17.

39 Se trata aquí de un límite a la estrategia de traducción defendida por Rawls en su concepto de razón pública, el cual de modo alguno impide la introducción de razones morales comprensivas (seculares o religiosas) en la arena política, pero impone la cláusula restrictiva que consiste en traducir las pretensiones morales amplias para el lenguaje del político, en vez de presentar "razones dadas únicamente por doctrinas comprensivas" (RAWLS, J. The Law of Peoples; with "The idea of public reason revisited", op. cit., p. 152; subrayado mío). 
en el entender de Habermas, la ética de la ciudadanía, que se define por las condiciones simétricas de participación en la práctica común de autodeterminación democrática, exige actitudes epistémicas de acuerdo con las cuales las disonancias cognitivas sean tratadas como desacuerdos razonables entre todas las partes involucradas en procesos de aprendizaje complementarios ${ }^{40}$.

\section{BIBLIOGRAFÍA}

BERTEN, A., DA SILVEIRA, P., POURTOIS, H. (1997) (eds.). Libéraux et communautariens. Paris: PUF, Collection "Philosophie Morale".

HABERMAS, J. "Religious Tolerance - The Pacemaker for Cultural Rights", op. cit., p. 17.

SWIFT, A. (1992), Liberals and Communitarians. Oxford: Blackwell.

TAYLOR, C. (1994), "The politics of recognition".

GUTMANN, A. (1992) (ed.). Multiculturalism: examining the politics of recognition. Princeton: Princeton University Press, pp. 25-73. "Politics of Recognition": An Essay. Princeton: Princeton University Press.

YOUNG, I., (1990) (J ustice and the Politics of Difference. Princeton: Princeton University Press, ).

HABERMAS, J. "Struggles for Recognition in the Democratic Constitutional State".

GUTMANN, A. (ed.). Multiculturalism: examining the politics of recognition, op. cit., pp. 107-148.

HABERMAS, J. The inclusion of the other: studies in political theory. Cambridge (Mass.): The MIT Press, edited by Ciaran Cronin and Pablo De Greiff, 1998, pp. 203-236.

BENHABIB, S.(2002), "Multiculturalism and Gendered Citizenship", in: The Claims of Culture: equality and diversity in the global era. Princeton: Princeton University Press. KYMLICKA, W. (1995), Multicultural Citizenship: a liberal theory of minority rights. Oxford: Clarendon Press.

KYMLICKA, W. Multicultural Citizenship: a liberal theory of minority rights. Oxford: Clarendon Press, 1995.

MILLER, D. (2003), On Nationality. Oxford: Oxford University Press, 1995; GANS, C. The Limits of Nationalism. Cambridge: Cambridge University Press.

HELD, D. (1995), Democracy and the Global Order: from the modern state to cosmopolitan governance. London: Polity Press.

RAWLS, J. (1999), The Law of Peoples; with "The idea of public reason revisited". Cambridge (Mass.): Harvard University Press. CRONIN, C. and DE GREIFF, P. (2002), (eds.). Global Justice and Transnational Politics: essays on the moral and political challenges of globalization. Cambridge (Mass.): The MIT Press.

HABERMAS, J. (1985), Der philosophische Diskurs der Moderne. Frankfurt: Suhrkamp.

El discurso filosófico de la modernidad. Madrid: Taurus, [trad. de Manuel Jiménez Redondo, 1989].

TAYLOR, C. (1989), Sources of the Self: the making of the modern identity. Cambridge (Mass. ): Harvard University Press.

HABERMAS, J. (1988). Nachmetaphysisches Denken. Frankfurt: Suhrkamp.

HABERMAS, J. "Struggles for Recognition in the Democratic Constitutional State", in: The inclusion of the other: studies in political theory, op. cit., pp. 207 y 210.

TAYLOR, C. "The politics of recognition", in: GUTMANN, A. (ed.). Multiculturalism: examining the politics of recognition, op. cit., pp. 66 y 68.

HABERMAS, J. (1992), Faktizität und Geltung. Beiträge zur Diskurstheorie des Rechts und des demokratischen Rechtsstaats. Frankfurt: Suhrkamp.

40 En el caso de los ciudadanos seculares, por ejemplo, eso exige asumir el hecho de habitar no solo un mundo pos-metafísico pero también pos-secular. Sobre el tema, muy presente en sus últimos escritos, cf. HABERMAS, J. "Religion in the Public Sphere" European J ournal of Philosophy, 14 (2006): 1-25. 
HABERMAS, J. Direito e Democracia: entre facticidade e validade, op. cit., vol. 2, p. 310.

HABERMAS, J. "On the relation between the nation, the rule of law and democracy", in: The inclusion of the other: studies in political theory, op. cit., pp. 129-153.

CONSTANT, B. "De la liberté des anciens comparée a la celle des modernes", in: De I'esprit de conquête et de l'usurpation. París: Flammarion, 1986, pp. 265-291 [La edición original es de 1819].

HABERMAS, J. Direito e Democracia: entre facticidade e validade, op. cit., vol. 1, p. 142.

HABERMAS, J . Erläuterungen zur Diskursethik, op. cit., pp. 100-118.

HABERMAS, J. Conciencia moral y acción comunicativa. Barcelona: Península, trad. de Ramón García Cotareto, 1985, pp. 85-86.

HABERMAS, J. Direito e Democracia: entre facticidade e validade, op. cit., vol. 1, p. 145.

HABERMAS, J. Direito e Democracia: entre facticidade e validade, op. cit., vol. 1, p. 158.

HABERMAS, J. Direito e Democracia: entre facticidade e validade, op. cit., vol. 2, p. 23. Idem, Ibidem, pp. 27 y 190.

OLIVEIRA, N.; SOUZA, D. G. (eds.). J ustiça e Política. Porto Alegre: EDIPUCRS, pp. 29-45.

BERTEN, A. "Républicanisme et motivation politique".

MERLE, J. C.; SCHUMACKER, B. (2001), (eds.). Figures du communautarisme. París: Ophrys. YOUNG, I. "Communication and the Other: Beyond Deliberative Democracy"

BENHABIB, S. (1996), (ed.). Democracy and difference: contesting the boundaries of the political. Princeton: Princeton University Press, pp. 120-135.

BAUMEISTER, A. (2003), "Habermas: Discourse and Cultural Diversity". Political Studies, 51 : 740-758.

THOMASSEN, L. (2006), "The Inclusion of the Other? Habermas and the Paradox of Tolerance". Political Theory, 34: 439-462.
HABERMAS, J. (2005), “Equal Treatment of Cultures and the Limits of Postmodern Liberalism". The Journal of Political Philosophy, 13.

MENKE, C. (2004), cuya bibliografía puede ser encontrada al largo de las dos primeras secciones del artículo de Habermas. Vide, entre uno y otro texto, el siguiente: "Religious Tolerance - The Pacemaker for Cultural Rights". Philosophy, 79: 5-18.

RAWLS, J. (1996), Political Liberalism. New York: Columbia University Press, paperback edition with a new introduction,

HABERMAS, J. "Equal Treatment of Cultures and the Limits of Postmodern Liberalism", op. cit., p. 16.

BARRY, B. Culture and Equality: an egalitarian critique of multiculturalism. Cambridge (Mass.): Harvard University Press, 2002, p. 36.

FRASER, N.; HONNETH, A. Redistribution or Recognition? A Political-Philosophical E XCHANGE. London: Verso, 2003.

KELLY, P. (2002), (ed.). Multiculturalism Reconsidered: 'Culture and Equality' and its Critics. Oxford: Polity Press.

HABERMAS, J. "Religious Tolerance - The Pacemaker for Cultural Rights", op. cit., p. 17.

RAWLS, J. The Law of Peoples; with "The idea of public reason revisited", op. cit., p. 152.

HABERMAS, J.(2006), "Religion in the Public Sphere". European J ournal of Philosophy, 14: 1-25. 